\title{
Managing Knowledge in a Business Intelligence Consulting Project
}

\author{
Andreas Schroeder \\ School of Business \\ University of Buckingham \\ Buckingham, United Kingdom \\ andreas.schroeder@buckingham.ac.uk \\ Yulin Fang \\ Department of Information Systems \\ College of Business \\ City University of Hong Kong \\ Hong Kong, China \\ Yulin.fang@cityu.edu.hk \\ Bryan Lee \\ College of Business \\ City University of Hong Kong and IBM Global Services \\ Hong Kong, China \\ bryanleekw@gmail.com
}

\begin{abstract}
IT projects require diverse knowledge resources, which need to be accessed, created, and shared. The lack of these knowledge resources or their inappropriate management is one of the main sources of project delays and even failure. The present case describes the situation of a challenging, but to some extent typical, business intelligence (BI) implementation project at Hong Kong International Airport. The case highlights the diverse knowledge-based challenges encountered during the implementation of the BI system and its implications for the further development of the project. The case is designed to introduce students to Reich's (2007) knowledge-based risk framework, which allows for a systematic analysis of knowledge-related issues in IT project environments. As knowledge has become a critical source of both shortand long-term competitive advantage for international enterprises (Fang et al. 2007), the analysis points to the diverse knowledge-based issues as the root causes of several problems the project is facing and indicates the complexity surrounding these knowledge issues. Extensive background information on the strategic position of the Hong Kong Airport and the potential role of BI technology provide the basis for further discussion and additional analyses.
\end{abstract}

(Teaching notes are available to instructors from the authors)

Keywords: Knowledge management, project management, knowledge risk 


\section{Introduction}

Nobody in the implementation team had expected the introduction of the business intelligence $(\mathrm{BI})$ system at Hong Kong (HK) International Airport to become such a risky project. In August 2008, the team finally handed over a fully functional $\mathrm{BI}$ system to the HK International Airport. However, Bob, the team leader of the implementation team, still had doubts that the project could be considered a complete success, as both the project schedule and the budget exceeded by a considerable margin. He knew from years of consulting experience that systemimplementation projects are very risky, and even supposedly straightforward projects often develop into exhausting enterprises. Still, he was puzzled about what had gone wrong in their project: How could what had looked like a simple and straightforward system implementation develop into such a complex and, at times, frustrating experience? What were the underlying issues that drove the project to the brink of failure?

\section{Company Overview}

HK Airport once had the reputation of being one of the world's most perilous international airports with planes appearing to fly between high-rise buildings to land at its inner city Kai Tak location. The spectacular landings are, in fact, commemorated in the popular flightsimulator games where the Kai-Tak landing is one of the most revered varieties of the game. However, in the 1980s, the Hong Kong government began to look for opportunities to build a new airport as the capacities of the Kai Tak location were exhausted due to the ever-increasing air traffic. Height restrictions around the airport likewise limited property development in its vicinity.

In 1989, the decision was made to construct the new airport on Chek Lap Kok, one of the nearby islands outside the city boundaries. The USD2-billion project stretched the limits of civil engineering as it required extensive land reclamation, as well as the construction of bridges and the development of rail networks in addition to the actual airport infrastructure. Despite the enormity of the construction task, the new airport went into operation nine years later in 1998. Subsequently, it has been widely considered as one of the world's best airports ${ }^{1}$, serving the financial city of Hong Kong, the South China region, and the entire world as a major transportation hub. The large investment that went into the construction of the new airport proved to be most worthwhile. HK International Airport has become one of the most profitable international airports, creating annual revenue of more than USD 1 billion from its diverse passenger, cargo, and retail operations (see appendix $1 \& 2$ ).

On average, 760 planes from 87 different international airlines take off or land daily, making HK International Airport the world's fifth busiest in terms of passenger number and the busiest in terms of cargo operations. As 36 percent of the airport's total revenue comes from passenger and cargo operations, they are the airport's best revenue sources. Most international freight forwarders use HK International Airport as a multi-modal transportation hub providing sea and land connectivity for cargo traffic. In addition to its role as a transportation hub, the airport also serves as an "Airport City" with business and entertainment venues, which has around 60 restaurants and 260 retail outlets to service both travelers and business residents. The airport's retail operations generate more than 25 percent of the total revenue and are expected to contribute to the largest growth in revenue in the near future.

Increasingly, other airports in the South China region are also eager to partake of the HK International Airport's lucrative passenger and cargo operations (see appendix 4). While the airport was originally considered to be the only international gateway to the South China region, a range of other airports in its vicinity are increasingly meeting international standards and pose a considerable threat to its de facto monopoly position. Just 110 miles to the north, the RMB2.4-billion (USD350 million) Baiyun International Airport reopened in 2004 and is expected to become a major cargo hub for the manufacturers 
located in the Pearl River Delta. Shanghai's Pudong Airport is trying to establish itself as China's primary passenger gateway. Even closer to Hong Kong, Shenzhen International Airport is creating competition for freight operations, and Macau is emerging as a favored center for budget airlines. Thus, the competition among airports in the South China region is fierce. A study commissioned by Hong Kong's Airport Authority has forecast that HK International Airport's cargo volume will nearly double by 2020 , but its share of the Pearl River Delta's total freight operation will slide from 90 percent to less than half (Cartledge, 2004).

To maintain its market share, $\mathrm{HK}$ International Airport has put a range of strategies in place. Most prominently, it seeks to develop its capabilities as an inter-modal transportation hub further, which can combine air, sea, and land transport. Direct coach services already transfer more than 6,000 passengers a day from $\mathrm{HK}$ International Airport to major cities and towns in the Guangdong region, such as Shenzhen, Dongguan, and Guangzhou. Direct ferry services carry cargo and passengers between the airport and a range of cities in the Pearl River Delta including Shekou, Shenzhen, and Macau. Skypier, a dedicated ferry terminal, transports 2.1 million transit passengers a year without going through immigration processes.

Managing an airport requires very careful consideration of a complex network of stakeholders and their requirements. The interests of passengers, airlines, cargo operators, and local businesses have to be considered, while the airport itself has to remain a profitable entity at the same time. Although these stakeholders are highly dependent on each other's success, their immediate interests may be incompatible. Quick connection times, for example, are appreciated by passengers but limit the opportunities for airport retail shops to do business with passengers. Considering the complex web of mutual dependencies and conflicting interests, airport management must be very careful in its strategic decision making.

The complexities under which HK International Airport operates are further aggravated by its ownership structure and regulatory framework. The Hong Kong Airport Authority is a statutory body wholly owned by the Government of Hong Kong Special Administrative Region. Large investments in the airport must be presented to the government and are subject to intense political scrutiny. Larger infrastructure investments are subjected to lengthy approval deliberations, which create further delays for already time-consuming development projects. In 1996, the management started to discuss the construction of a new runway to increase the airport's capacity and maintain its competitive position. So far, no decision has yet been reached. However, even after a decision had been made, it would take approximately 12 years to build the new runway considering the initial planning and design, public consultation, and construction.

\section{Business Intelligence at $\mathrm{HK}$ International Airport}

Making strategic decisions in such complex scenarios requires high quality business intelligence (BI) [See (Chung 2009) for details about BI]. Different from traditional knowledge management techniques such as knowledge repositories (He et al., 2009), BI is skills, technologies, applications, and practices used to help a business acquire a better understanding and forecasting of its commercial context, and is therefore a solution for knowledge discovery. HK Airport must excel in knowledge discovery so as to facilitate strategic decision making in the complex environment. The long-term focus of HK International Airport's planning activities, the intense level of public scrutiny of its decision making, and the large amount invested in the facility do not leave much room for uncertainties in forecasting future airport operations. To assess the demand for additional ferry and coach services to mainland China or new cargo-loading 
facilities, the decision makers at $\mathrm{HK}$ International Airport need to be able to judge the current utilization rate of their facilities and make sound estimates about long-term developments. Current and reliable statistics on passenger and cargo numbers, their origins, and destinations are essential.

Moreover, HK International Airport's business partners, such as airport retailers, require reliable data on the development of passenger numbers and their flow patterns to adjust their operations and marketing efforts accordingly. Product selection or promotional activities require careful consideration of both long-term and short-term trends in passenger volume and origins. Similarly, data on passenger volume, origins, and destinations are required by the Immigration Department to optimize further their control operations. $\mathrm{HK}$ International Airport is thus a provider of vital data and information for a wide range of stakeholders, which puts further pressure on the airport's ability to conduct high-level business analysis.

\section{The Airport Operation Statistics System (AOSS)}

The management at HK International Airport was aware of the importance of high-quality data analysis. On the first day of its Chek Lap Kok operations in 1997, dedicated systems were put in place. The Airport Operation Statistics System (AOSS) was commissioned under the command of the Strategic Planning Department, an advisory body to the chief executive officer (CEO) charged with providing daily reports on the throughput and with forecasting long-term developments. Based on these reports and forecasts, the CEO could maintain an overview of the airport operations and make informed adjustments. The AOSS allowed the department to collect, store, and process diverse sets of operational data, especially data on flight movements, and details of passenger and cargo movement. The database was fashioned after the Oracle 9 relational database management system, which defines data structure and the relationships between data. By 2007, around
$15 \mathrm{~GB}$ of data were stored in the database, including two years of transactional data and 10 years of pre-processed data in the form of reports.

\section{Data management issues of AOSS}

Despite providing valuable information on the airport's key operations, the system had several analytical limitations. Most significantly, the system could not establish relationships between data from different sources. It could show the distribution and development of passenger numbers but could not integrate these developments with data on flight operations to show how flight origins and passenger numbers relate. When staff at the Statistics Department spotted a significant increase in passenger numbers, they were unable to identify which airlines or which geographical areas contributed to this surge. The airport's strategic management not only requires a system that shows the trends but also one that explains these trends to assess the opportunities.

Over the years, dissatisfaction about the system grew among the staff at the Strategic Planning Department, especially with the tedious procedures for data handling and integration. Relevant operational data were created and stored in different systems owned by the airport and its various business partners. To load passenger and cargo data into the AOSS, data had to be extracted first from these diverse upstream systems and then transformed into the AOSS data structure so that it could be loaded into the database. Other systems used different formats, and the staff had to ensure that the diverse data formats were compatible once they were integrated in the AOSS system. Simple variations in the way data were recorded could already create difficulties in integrating such data at a later stage. A software system, DataStage, was used to facilitate this complex extraction, transformation, and loading tasks (ETL).

Despite using the ETL software, the disparate data sources and diverse data formats created several challenges for data 
integration and the subsequent data analysis. Since the software's original development, the number and diversity of the AOSS' upstream data sources increased considerably, making the necessary data cleansing and data transformation processes very difficult to conduct. Data from airlines and cargo operators could only be subjected to preliminary cleaning; the transformation processes and the loading of data, which was not fully compatible, were therefore permitted. During the data-loading process, inconsistencies among the flight schedules were highlighted, requiring the Strategic Planning staff to manually check and confirm the accuracy of the data with the airline or freight operators. Even after the loading procedure, the data remained the property of the business partners and could not be altered without consensus. This made it even more difficult for the HK Airport Authority to deal with the diverse and inconsistent data sources efficiently.

\section{Data analysis issues of AOSS}

Data analysis was another area where the insufficiencies of the AOSS were apparent. Data in the system could only be accessed through complex queries, which had to be specifically programmed and carefully administered. The Strategic Planning staff lacked these skills, were not able to access the database directly, and had to involve the Information Technology (IT) department. The IT department would run the standard queries at regular intervals and forward the extracted data to the Strategic Planning Department. Non-standard queries had to be individually programmed, which often took several days to complete. The Strategic Planning staff had to wait for the extracted data before they could perform further processing and start with the required analyses. Furthermore, AOSS data could only be extracted in the form of an unusual text files, and thus the staff needed to transform the data into a standard table format before they could use conventional desktop applications such as Microsoft Excel to perform further analysis.
Analyzing the data with AOSS required considerable hands-on involvement, and was very time-consuming and labor-intensive. Some of the Strategic Planning staff had to arrive two hours before regular office hours to have enough time to perform the analyses for the daily reports to the CEO. Younger staff members were very reluctant to get involved in these exasperating processes, and the management came to realize that the Hong Kong Airport Authority's analytical capabilities would be jeopardized should any of the experienced analysts resign. Concerns about the data accuracy became apparent over the years. As the airlines and cargo companies provided their data at different weekly or monthly intervals, the data in the AOSS were technically never up-to-date, and the most recent data from one or more of the partners were always lacking. To create complete reports from the remaining data, analysts had to project the missing data from previous records. This practice of "projecting data" reduced the reports' accuracy and made them less sensitive to recent developments.

\section{Conceptualising the new AOSS}

The increasing importance business analysis would play in airport management and strategic planning made it obvious that the AOSS system required replacement. Since its original implementation in 1997, advanced BI tools have become available, which provide highly efficient data processing and analytical capabilities. To address the inefficiencies and risks created by the original AOSS, the head of the Strategic Planning Department in 2007 secured funding for the development of a new AOSS system (AOSS2). The immediate objective of the new system was to increase the efficiency of the analytical operations with the additional objective of creating new $\mathrm{BI}$ functions and capabilities.

The department envisioned the AOSS2 to be a system that would allow them to query the data directly without the involvement of the IT department; analyze the data through an intuitive graphical user interface, which would allow for ad hoc queries without the need for programming specific queries; and perform 
analysis within an integrated system that would free them from importing data into secondary desktop applications, allowing them to save, share, and reuse queries and results.

The AOSS2 should also provide new analytical insights by integrating the diverse sets of available data sources and analyzing their relationships. The areas of air traffic, cargo, passengers, and even visiting passengers are tightly interrelated areas of operations whose trends need to be monitored in relation to each other (see appendix 5 showing the relationships among these areas). In the long term, the system should also be able to integrate financial data to create a better understanding of the financial implications of passenger and cargo flows (see appendix 6 for a list of expected benefits of the new system). The AOSS2 was conceptualized as a "one-stop-shop" for the diverse corporate data requirements that would even provide direct, self-service access for the different departments to perform their analyses.

Meeting these diverse objectives would require a substantial re-organization of the original AOSS. First, a data warehouse had to be established to capture and integrate data from the different databases for analysis. The data warehouse required a new data structure and the creation of new interfaces to import the diverse operational raw data. A sophisticated BI application that would provide the interface capabilities and tools for staff queries and data analysis had to be implemented and integrated with the underlying data warehouse. To make full use of these new tools and applications, many of the established business processes had to be redesigned, and many established working practices of the HK Airport staff would need to be adjusted accordingly.

\section{The Project Setup}

It was clear from the beginning that a project of this complexity and magnitude could not be carried out by the HK International Airport staff alone. Although the airport had a sizeable IT department, its expertise was mainly focused on the administration and maintenance of existing systems, and the staff had little knowledge of new developments in the $\mathrm{BI}$ domain. Implementing a $\mathrm{BI}$ solution is a very knowledge-intensive undertaking because it not only concerns the BI system itself but also the underlying database architecture, interfaces with other systems, and related business processes.

To obtain the necessary expertise in $\mathrm{BI}$, data warehousing, database architecture, and business process reengineering, it was decided to collaborate with an outside consulting partner and requests for proposal were sent to both local and international consulting companies. The requests for proposal outlined the project as an average BI implementation worth USD 600,000 with an implementation timeframe of eight months. The key objectives of the project required to: 1) re-architecture the database; 2 ) implement the new user functionalities; 3) improve information availability and accessibility; 4) streamline existing data preparation process. The HK Airport received a range of very competitive bids for the $\mathrm{Bl}$ implementation project, with companies undercutting each other by up to 50 percent. Decision makers at HK Airport focused on reputation and expertise in the $\mathrm{BI}$ field, and the feasibility of the specific solutions they proposed. Costs were considered only as a secondary criterion. The implementation of the project was eventually awarded to the international consulting company where Bob worked as a senior consultant and BI specialist. An outline of the consultant's responsibilities in the project is provided in appendix 7 .

\section{Project team formation}

In August 2007 the project was kicked off with the formation of the project team that included consultants and HK Airport staff. In addition to nominating Bob as a team leader and system architect, the consulting company dedicated seven other members to the project team: an experienced project manager to coordinate the project and liaise with the project head; a seasoned business 
analyst to collect user requirements; a web developer to design the user interfaces; a tester to verify user acceptance and the quality of the system integration; and three newly graduated trainees who would take on the various development tasks after receiving initial on-the-job training.

Apart from the new graduates, all the staff members had more than five years of systems implementation experience in different industries, although none of them in the transport industry. Only Bob, as a systems analyst, had extensive expertise in the $\mathrm{BI}$ domain. Other staff members had obtained their project experience in other enterprise-wide systems such as Enterprise Resource Planning (ERP) or Customer Relationship Management (CRM). In 2007, very few experts in the $\mathrm{BI}$ domain were available when the $\mathrm{BI}$ market boomed and began to be established as a consulting area. Consequently, Bob was expected to provide the necessary BI-specific insights over the course of the project.

HK International Airport contributed four experienced IT staff to the project: a project manager was nominated to oversee the resource management and monitor the activities of the consulting partner; two systems analysts focused on identifying the various business requirements and providing technical support for server installations; and one data conversion manager was responsible for the cleaning and consolidation of the data. Selected staff members from the Strategic Planning Department were also assigned to the project to provide a user's perspective.

\section{Collaboration Challenges}

Although, technically, consultants and the internal staff formed one project team, it became very clear that the stringent security arrangements at $\mathrm{HK}$ International Airport prevented the common project arrangement where consultants work "on site" and mix with the client team members. In this case, the consultants could not work on the airport premises due to the high security requirements and were placed on a different site separate from the airport staff. During the production phase of the project, the entire team would only meet every two weeks; during the project's initial stages, meetings were even less frequent. The consultants established a virtual team room to facilitate their collaboration but could not provide the airport staff with access to this facility due to intellectual property restrictions. For most of the project, the two parts of the team could only communicate through e-mails and phone calls.

To oversee the progress of the project and track its development, a steering committee was set up. The steering committee was composed of senior managers from the airport and representatives from the consulting partner. It included the head of the Strategic Planning Department as the project leader, the IT systems manager, and some other senior airport managers. From the consulting company's side, two project executives, who were occasionally joined by their associate partners, formed part of the steering committee. The committee members had extensive experience in airport business and systems implementation but lacked specific BI expertise. The committee convened every two months to discuss the scope and schedule of the project but did not become involved in the project's day-to-day challenges.

\section{Designing and Implementing The BI System}

Project implementation can be divided into three major phases: (1) the identification of the user requirements, (2) the analysis of the database, and (3) the actual implementation of the new system.

\section{Identification of User Requirements}

The focus of the first project phase was to identify the diverse stakeholders of the proposed system and clarify their expectations. By the end of August 2007, Bob and other selected members of the project team formed a smaller business team to identify systematically the specific ways 
airport staff used the old AOSS system and how they would expect the new AOSS2 system to operate. The business team initiated the requirement gathering by interviewing the manager of the Strategic Planning Department to identify the anticipated role of the system and the criteria on which a successfully designed and implemented new system would be assessed. The team also conducted several meetings with senior managers from other departments to understand better the nature of their business challenges and to discuss how the new system could assist them in the near future.

The business team next focused on identifying the pattern of the existing workflows and the processes for data handling and analysis. Of particular interest were the processes used for the cleansing of data, which came from diverse upstream data sources and the loading of data into the database; the integration of new data with the previously loaded data; and the handling of exceptions and inconsistencies. Also of interest were the processes used to retrieve raw data, the steps performed in the data transformation and analysis, and the variety of reports created from the data.

To gain a good understanding of the complex workflows created by these different processes, the business team conducted a series of interviews and workshops with the IT and the Strategic Planning Department staff. However, identifying and analyzing these processes required more effort and care than anticipated because hardly any of the processes were documented. Over the years, staff from the strategy department developed complex, undocumented workaround solutions to overcome the limitations of the present system. Explaining these idiosyncratic steps to the consultants and creating comprehensive flow charts that the consultants could use for analysis of the business processes proved to be very challenging. Bob remembers how his team struggled to understand what was actually happening with the data:
"Every time we thought that we got it, they would show us a new variation of their activities."

Nevertheless, by the end of September, the analysis of the business processes was completed, and the consultants prepared the detailed documentation of the user requirements, which was returned to the users for confirmation.

\section{Database Analysis}

After the user requirements and expectations for the new system were captured, Bob formed a technical sub-team to analyze the underlying database, data structure, data quality, and technical foundation. The new AOSS system should be an extension of the existing database, and it was important to obtain a very thorough understanding of the strengths and weaknesses of both its structure and content. Much like with the analysis of the user requirements, Bob's team could only get hold of very little documentation on the database. During its original implementation stage in 1998, the system was set up under a very tight schedule, and the original project team had simply skipped the formal documentation processes in order to focus on delivering the working system on time. Over the years, changing requirements created a range of further alterations to the database, which introduced further idiosyncrasies. Being the database expert, Bob had to spend a considerable amount of time and effort in analyzing the data structure and tracing the internal processes of the database.

Based on the insights gathered from the technical analyses, it became evident to Bob and the project team that a substantial redesign of the database was required to ensure the expected flexibility of the new AOSS2 system:

"The way the database was set up, very few of the expected operations would function... the data could not be put into relationship." 
The current workflow patterns were found to be very inefficient and had to be reengineered to ensure that its users could efficiently interact with the new system. After having gathered all the analysis in October, the project team began to realize that the project implementation would be more extensive than they had anticipated. Bob was very dissatisfied with the original project scope, which had been prepared without a BI specialist involvement:

"They underestimated the project as they thought they only had a few systems to update and ignored the complexity of the data in the project."

The design of the new system required substantial modifications to the database structure, the specific configurations of the BI system and data warehouse, and the reorganization of the associated workflows. As the decisions in any of these domains had an impact on other domains, design modifications required careful consideration of the different options and their related tradeoffs. Appendix 8 presents an excerpt of the AOSS2 database design (an overview of the database structure is provided in appendix 9).

A critical concern in the design phase of the project was the lack of $\mathrm{BI}$ expertise among the airport-based team members, which started to create major disruptions in the progress of the systems design. This made it difficult for the airport staff to commit to particular design features, and they required extensive clarifications to understand the wider implications of particular design decisions. The complexity and far-reaching consequences of the various design decisions forced the airport team members to seek confirmation repeatedly from system users, various stakeholders, and senior management, further delaying the project. The arduous design process created considerable tension between the airport and consulting team members. The airport staff at the time specifically complained how the consulting partners at times put undue pressure on them to make quick decisions, which was in marked contrast to the considerate working environment typical in an airport.

\section{Implementing the BI system}

When the overall design was approved in January 2008, the project was already three months behind schedule. Despite the extensive effort that had been put into the overall system design, the implementation process also proved to be difficult and unexpectedly slow. The project owners selected a widely used software product called DataStage as the data warehouse management system, which the implementation team had experience with. Shortly before the implementation stage, however, the project owner selected a new version of DataStage (version 8) for its wider range of functionalities. The new software version contained a number of differences and, at the time of its release, little detailed documentation was available, which created considerable difficulties for the project team. At the time of the implementation at $\mathrm{HK}$ International Airport, the latest version had only been implemented in very few organizations, and it still contained a number of bugs that had not been identified during vendor-based testing. To push forward with the implementation stage, the project team had to maintain a close link with the DataStage technical support staff, which was called upon as required to develop patches and provide background information to the project team members.

\section{Prototyping}

Although slower than anticipated, the project team managed to make progress with the implementation and was able to present initial prototypes and first sample reports to the airport authority in March. Upon seeing the first samples and experiencing the new system, the airport staff began to raise concerns, as some of the functions did not match their actual business requirements and demanded adjustments. The more the airport staff reviewed and practiced with the emerging prototypes, the better the understanding they developed of the $\mathrm{BI}$ 
concept and its capabilities. During these practice sessions, ideas for additional functionalities emerged, which led to a range of further requests for modification. Some of these modifications could easily be addressed by the implementation team; others, which seemed to be small adjustments, required major modifications to the system's underlying processes and database structure. Adding data to the report that were not yet available in the data warehouse required the creation of new processes for extracting the data from the original database.

One particular argument erupted when the airport staff requested a web-interface to allow for the manual modification of the flight data in the data warehouse. Bob and his team tried to argue that data in the warehouse should be considered authoritative and should not be modified at all. Several applications and reports would be based on the data in the warehouse, and allowing users to manually modify the source data would create inaccuracies among reports. The staff from the Strategic Planning Department kept insisting that such manual modifications would instead improve the quality of the data as their inaccuracies would successively be removed. While the original project scope only included fully automated data loading processes the consultants eventually accepted the request for building an interface for manual data modification. The consultants were concerned that negotiations on this issue would further delay the project even though the building of the manual data modification capability required substantial changes to the overall systems design.

The emerging user requirements and subsequent system adjustments created considerable additional workload for the implementation team, specifically for Bob as the $\mathrm{BI}$ specialist. It was originally planned that he would train the new graduates on the job so they would become productive team members and assist with the implementation. During the course of the project, however, he was continually engaged in solving immediate problems and had little time available for such on-the-job training. The tight project budget had no provision for the recruitment of additional staff to provide further support for the team. Worse, a number of consultants had already left within the first six months of the project as they were only sub-contractors who had accepted new assignments. Even more disruptive was the turnover among project managers. While one project manager left for personal reasons early on, two project managers had to be withdrawn from the project after complaints from the airport side. One project manager became frequently impatient in meetings with the airport staff who felt that he would not consider their requests and acknowledge their business expertise. The other project manager failed to convince the airport side of her $\mathrm{BI}$ expertise. Considering the number of replacements over the course of the project, Bob was the only project member who stayed throughout the entire project.

\section{System Delivery}

As the project was stretched for expertise and resources, project members came under considerable pressure to "deliver". In such an environment, quality assurance steps, especially the documentation of completed work items, could not be maintained anymore.

"Although there are guidelines of good practice in projects, the main focus of [the consulting company] is about project delivery,"

Bob remarked. As there was a lack of proper documentation, incoming team members were forced to spend much time tracing the path of some of the work that had already been done in order to understand the solutions adopted.

In April, halfway through the implementation process, the underlying tensions between the consultants and the airport team escalated. At this point, the consultants started to become openly critical of the many incoming change requests, while the airport staff formally complained of the lack of responsiveness and slow progress of the 
consultants. The airport side doubted the consultants would be able to complete the implementation successfully. A high-level

management of the airport was held to discuss the pending termination of the project. In the end, the two sides reinforced their commitment to the project, with one of the consulting partners temporarily taking on the leadership of the project to reassure the client. Within the consulting team, the temporary assignment of the partner did not help address their frustration. Request for modification continued to the usability-testing stage, leaving the consultants struggling until the implementation was completed.

\section{The Project Outcome}

After 12 months of intensive work, the project was completed, and HK International Airport finally had a working $\mathrm{BI}$ solution. Upon completion, the project was six months delayed, and several contingency budgets had to be put in place as more resources were required than anticipated.

Still, Bob and his team delivered a working $\mathrm{BI}$ solution, which stored and integrated data from the diverse operational systems and allowed querying across different modes of transportation and operators. The new system also provided full automation of the whole data loading and cleansing process, and a dashboard view of the data with quick overviews and drill down capabilities (see appendix 10 for a list of the functionalities of the AOSS2 and appendix 11 for an illustration of the dashboard view). This was a marked improvement from the old system with its manual loading processes and inability to

\section{References}

Cartledge, S. (2004) High Times For Hong Kong's Airport. BusinessWeek.

Chung, W. (2009) "Enhancing Business Intelligence Quality with Visualization: An Experiment on Stakeholder Network Analysis," Asia Pacific Journal meeting between the managing partners of the consulting company and the senior

integrate diverse data sources (see appendix 12 for a comparison between the two systems). The AOSS2 successfully provided the Statistics Department staff with the flexibility to carry out timely ad hoc analysis and to respond to queries from the different stakeholders in an efficient way.

In comparison with the many other implementation projects that were not able to deliver a functional system, the project claimed itself a success. However, among Bob and his team members, there was a high level of doubt regarding the success of the project. In addition to being completed well over time and budget, the team members had been forced to work very long hours and had experienced high levels of stress and conflict. As Bob leaves this project and rushes to the next, he attempts to determine who should be blamed for the unfortunate developments, which are typical in most projects, they had experienced and how such problems could be avoided.

${ }^{1}$ In 2001-2005 and 2007-2008, HK International Airport ranked first in the Skytrax's World Airport Awards.

\section{Acknowledgement}

The work described in this paper was partially supported by a grant from the Research Grants Council of the Hong Kong Special Administrative Region, China (Project No. CityU 142208)

of the Association for Information Systems, 1 (1), pp.33-53

Fang, Y., Wade, M., Delios, A., and Beamish, P.W., (2007) "International Diversification, Subsidiary Performance, and the Mobility of Knowledge Resources," Strategic 
Pacific Asia Journal of the Association for Information Systems, Vol. 1, Iss. 3 [2009], Art. 4

Managing Knowledge in a Business Intelligence Consulting Project/ Schroeder et al.

Management Journal, 28 (10), pp. 1053-1064

He, W., Fang., Y., and Wei, K.K., (2009) "The Role of Trust in Promoting Organizational Knowledge Seeking Using Knowledge Management Systems: An Empirical Investigation," Journal of the American Society for
Information Science and Technology, 60 (3), pp.526-537.

HK International Airport. (2008) Annual Report.

Horner Reich, B. (2007) "Managing knowledge and learning in IT projects: A conceptual framework and guidelines for practice," Project Management Journal, 38 (2), pp.5-17 


\section{Appendix 1: Financial Statement}

\begin{tabular}{|c|c|c|c|}
\hline $\begin{array}{l}\text { Financial Summary } \\
\text { Year ended } 31 \text { March } \\
\text { (in HK\$ million) }\end{array}$ & $2007 / 08$ & $2006 / 07$ & $\pm \%{ }^{1}$ \\
\hline Turnover & 8,577 & 7,738 & $+11 \%$ \\
\hline $\begin{array}{l}\text { Operating expenses before depreciation and } \\
\text { amortisation }\end{array}$ & 3,292 & 3,085 & $+7 \%$ \\
\hline $\begin{array}{l}\text { Operating profit before depreciation and } \\
\text { amortisation }\end{array}$ & 5,285 & 4,653 & $+14 \%$ \\
\hline Depreciation and amortisation & 2,307 & 2,014 & $+15 \%$ \\
\hline Interest and finance charges & 425 & 378 & $+12 \%$ \\
\hline Share of profits of a jointly controlled entity ${ }^{2}$ & 89 & 88 & $+1 \%$ \\
\hline Profit before taxation & 2,642 & 2,349 & $+12 \%$ \\
\hline Income tax & 374 & 430 & $-13 \%$ \\
\hline Profit for the year & 2,268 & 1,919 & $+18 \%$ \\
\hline Profit attributable to equity shareholder & 2,273 & 1,920 & $+18 \%$ \\
\hline Dividend declared & 2,000 & 1,600 & $+25 \%$ \\
\hline \multicolumn{4}{|l|}{ Key Financial Ratios } \\
\hline Return on equity & $6.5 \%$ & $5.6 \%$ & \\
\hline Total debt/capital ratio & $23 \%$ & $24 \%$ & \\
\hline \multicolumn{4}{|l|}{ Key Traffic Summary ${ }^{3}$} \\
\hline Total passengers ${ }^{4}$ (million) & 48.9 & 45.1 & $+8 \%$ \\
\hline Cargo tonnage $^{5}$ (million) & 3.8 & 3.6 & $+6 \%$ \\
\hline Air traffic movements (thousand) & 300 & 283 & $+6 \%$ \\
\hline \multicolumn{4}{|c|}{$\begin{array}{l}1 \text { Subject to rounding differences. } \\
2 \text { In } 2007 / 08 \text {, "Share of profits of a jointly controlled entity" includes the nine months from } 1 \text { April } 2007 \text { to } \\
31 \text { December } 2007 . \text { Figure for } 2006 / 07 \text { includes the four months from the date of acquisition to } 31 \text { March } \\
2007 . \\
3 \text { "Key Traffic Summary" is based on Airport Authority's traffic data of Hong Kong International Airport only. } \\
4 \text { "Total passengers" includes originating, terminating, transfer and transit passengers. Transfer and transit } \\
\text { passengers are counted twice. } \\
5 \text { "Cargo tonnage" includes originating, terminating and transshipment cargo. Transshipment cargo is counted } \\
\text { twice. Airmail is excluded. }\end{array}$} \\
\hline (HK International Airport, 2008) & & & \\
\hline
\end{tabular}




\section{Appendix 2: Overview of Revenue Sources}
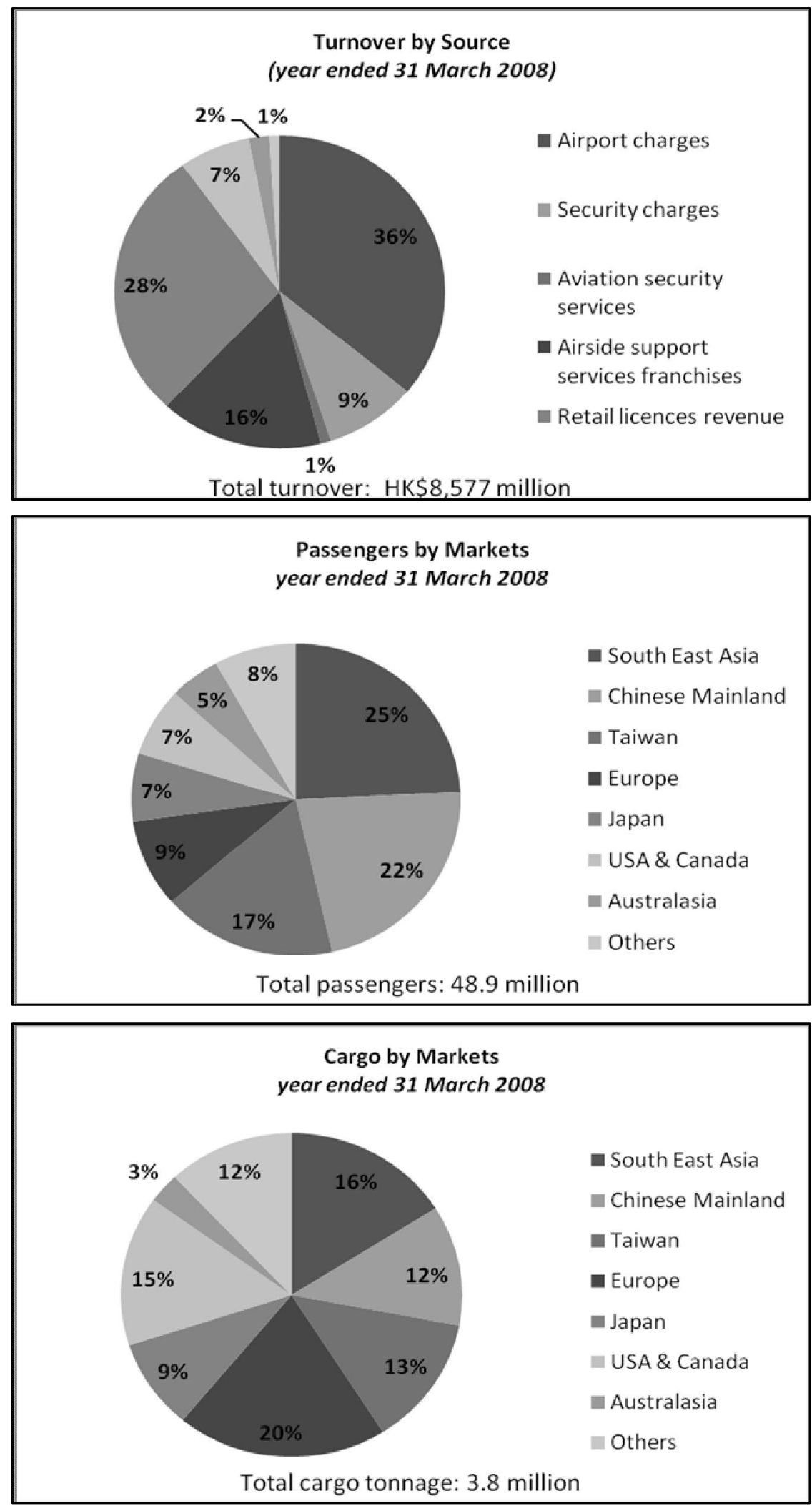

(HK International Airport, 2008) 


\section{Appendix 3: Air-Traffic Development}
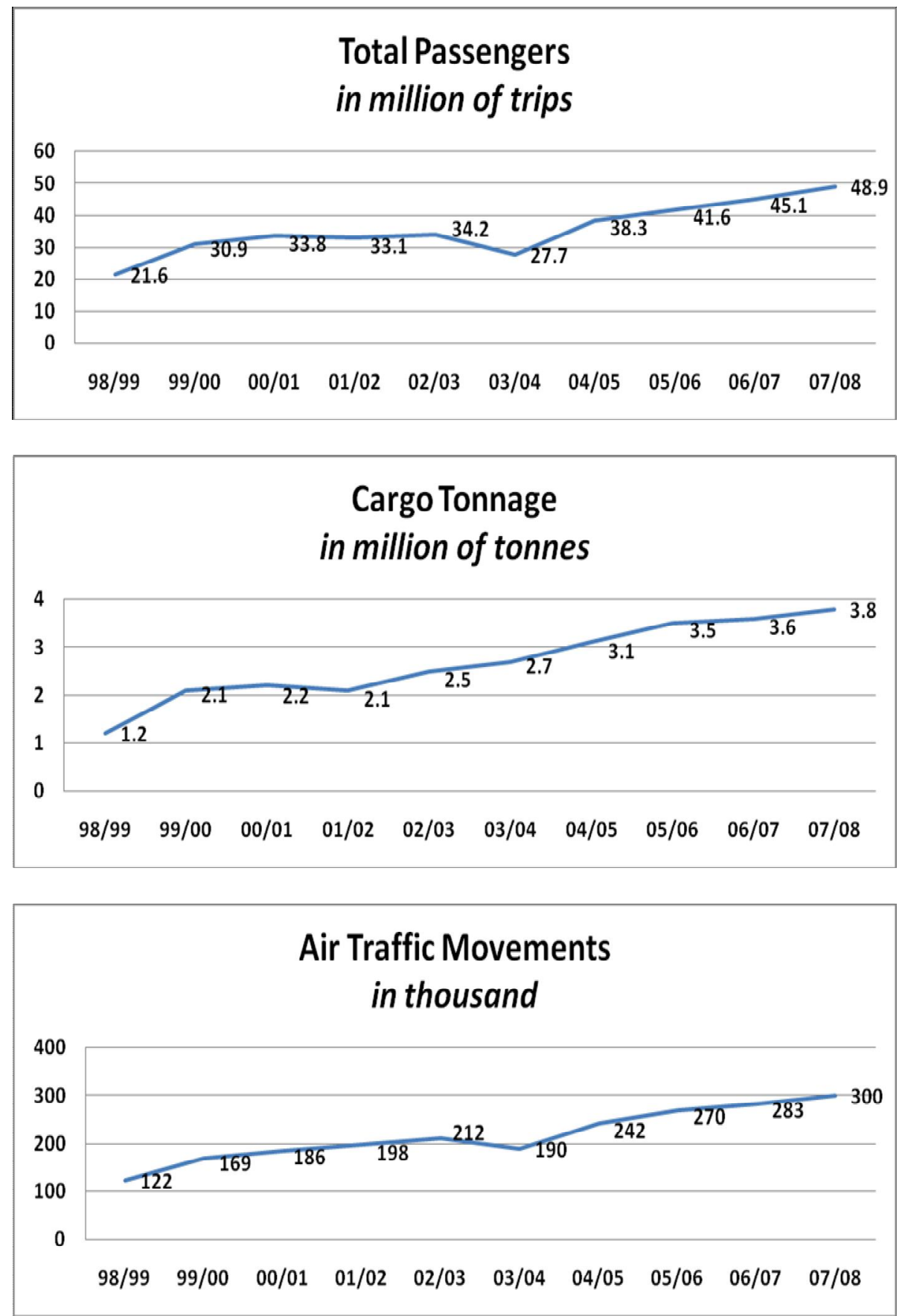

(HK International Airport, 2008) 


\section{Appendix 4: Map Showing The Major Airports In South China}

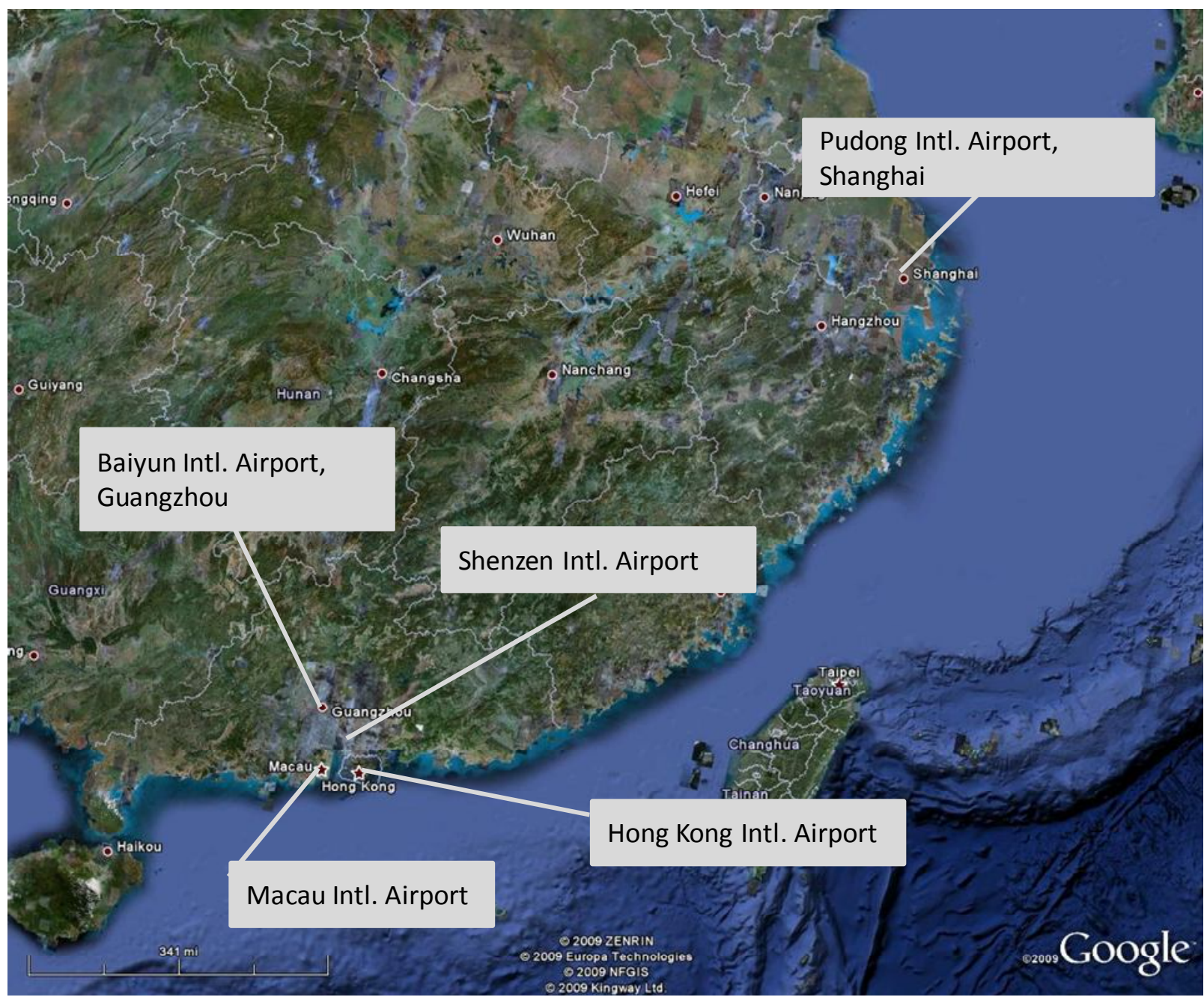




\section{Appendix 5: Relationships among Areas of Data}

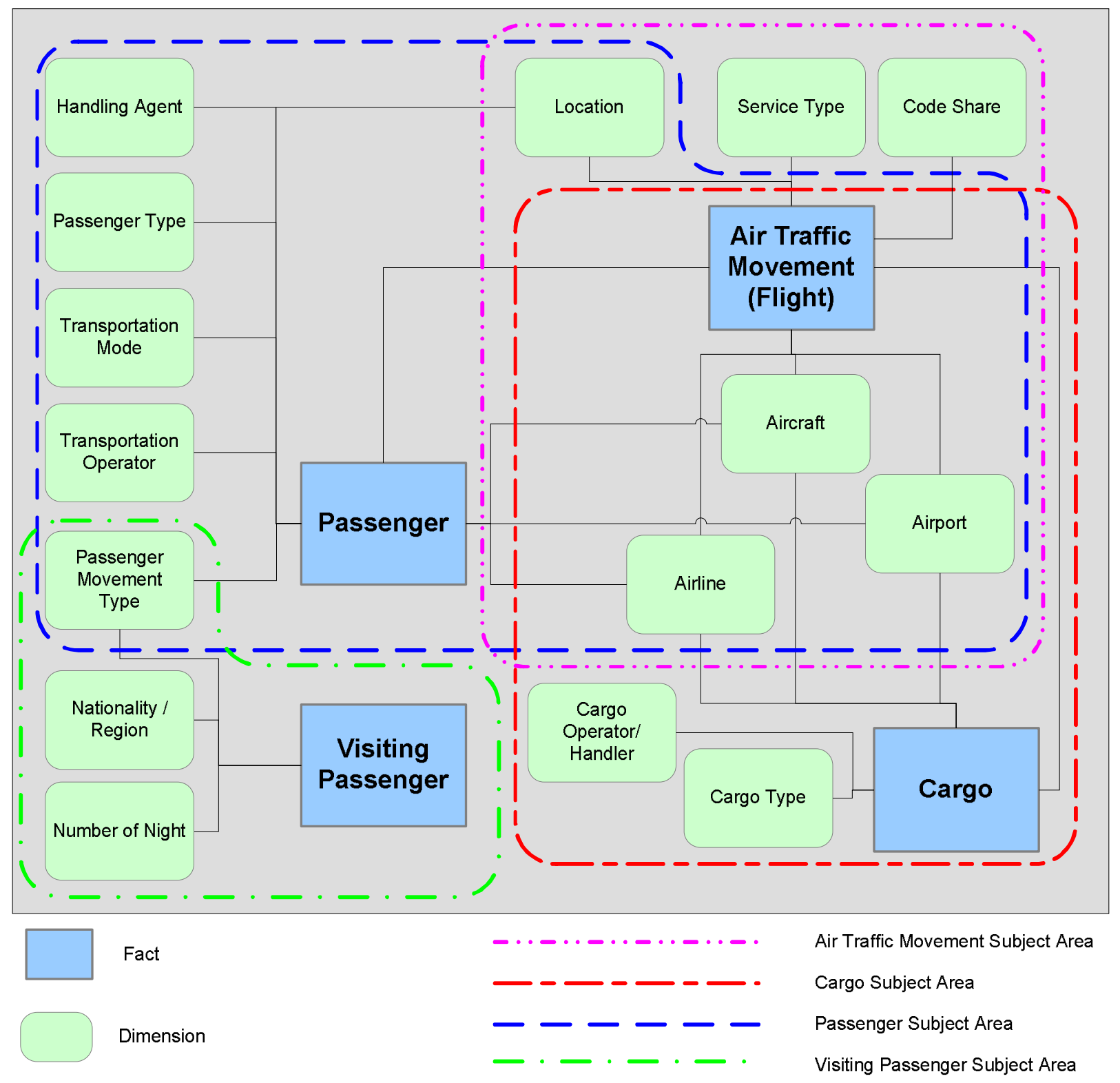




\section{Appendix 6: Expected Benefits of Aoss2}

\section{Benefited Users}

- Senior Management

- Operation Manager

- Business Analyst

- Airport Planner

- Airfield Officer

- Extra Users, such as Immigration dept, BAC, GFS, Air Mail Center etc

\section{Business Benefits}

- Analysis of the Flight, Passenger and Cargo Information by Airline/ by Airport/ by Aircraft/ by DateTime/ by Location/ by Service Type, by Flight Log/ by Cargo Operator and Handler/ by Transportation Operator etc.

- Intermodal Passenger Transport between transportation operators

- Streamline the viewing of various Provisional, Budget, Finalized report

- Future extension for Cross Departmental Data or Performance Analysis, like Finance, HR, etc.

- Key Performance Indicator implemented on various business areas

- Simplified Data Loading Processes with extra parties such as Immigration department, cargo operators, business aviation center etc 


\section{Appendix 7: Responsibilities of The Consultants}

\begin{tabular}{|c|c|}
\hline $\begin{array}{l}\text { Consultants } \\
\text { Responsibilities }\end{array}$ & Tasks \\
\hline $\begin{array}{l}\text { Perform Project } \\
\text { Management }\end{array}$ & $\begin{array}{l}\text { - Conduct project management, status meeting and provide project status } \\
\text { - Establish documentation and procedural standards for deliverable materials } \\
\text { - Submit and update project plan } \\
\text { - Coordinate and manage project personnel }\end{array}$ \\
\hline $\begin{array}{l}\text { Perform } \\
\text { Requirement } \\
\text { Analysis }\end{array}$ & $\begin{array}{l}\text { - Conduct interviews and workshops with major users of AOSS to analyze business } \\
\text { requirements } \\
\text { - Identify improvement areas to meet future requirement growth } \\
\text { - Review existing system, standard and ad-hoc reports } \\
\text { - Define the requirement components (database model requirements, report requirements, } \\
\text { interface and validation requirements, security requirements, administration and user } \\
\text { interface requirements) }\end{array}$ \\
\hline $\begin{array}{l}\text { Perform Solution } \\
\text { Design }\end{array}$ & $\begin{array}{l}\text { - Perform logical and physical design for the following AOSS2 components (data model, } \\
\text { interface and validation programs, reports, administration and user interface components) } \\
\text { - Specify data extraction requirements and specification to implement data extraction } \\
\text { programs }\end{array}$ \\
\hline $\begin{array}{l}\text { Perform Solution } \\
\text { Build }\end{array}$ & $\begin{array}{l}\text { - Develop and perform unit test on the interface and validation programs } \\
\text { - Develop and perform unit test on the reports } \\
\text { - Develop fixes to correct problems encountered during the tests }\end{array}$ \\
\hline $\begin{array}{l}\text { Perform System } \\
\text { Integration Test }\end{array}$ & $\begin{array}{l}\text { - Develop the SIT Test Plan and associated test cases } \\
\text { - Release programs to the SIT environment } \\
\text { - Conduct SIT according to the SIT Test Plan } \\
\text { - Resolve defects found during the SIT } \\
\text { - Prepare SIT Test Report } \\
\text { - Prepare SIT System Release Notes }\end{array}$ \\
\hline $\begin{array}{l}\text { Support the } \\
\text { Authority on User } \\
\text { Acceptance Test } \\
\text { (UAT) }\end{array}$ & $\begin{array}{l}\text { - Develop UAT Test Plan and review with the Authority } \\
\text { - Create test scripts which include test conditions, test procedures, test data and expected } \\
\text { test results } \\
\text { - Investigate UAT problems reported by the Authority UAT testers } \\
\text { - Resolve defects caused by IBM under this SOW } \\
\text { - Compile the User Acceptance Test Report, which summarizes the test results } \\
\text { - Prepare UAT System Release Notes }\end{array}$ \\
\hline $\begin{array}{l}\text { Perform Production } \\
\text { Implementation } \\
\text { (PRD) }\end{array}$ & $\begin{array}{l}\text { - Document operational and maintenance procedures for interfaces and reports } \\
\text { - Prepare Product System Release Note } \\
\text { - Release programs to the production environment prepared by the Authority } \\
\text { - Provide procedures to monitor the healthiness of the System }\end{array}$ \\
\hline $\begin{array}{l}\text { Provide Application } \\
\text { Training }\end{array}$ & $\begin{array}{l}\text { - Document User Manual } \\
\text { - Conduct trainings }\end{array}$ \\
\hline Convert AOSS Data & $\begin{array}{l}\text { - Analyze data conversion requirements } \\
\text { - Develop data conversion specification } \\
\text { - Manage the Authority's resources to implement data conversion programs } \\
\text { - Work with the Authority to coordinate data conversion execution }\end{array}$ \\
\hline $\begin{array}{l}\text { Provide Post- } \\
\text { Implementation } \\
\text { Support }\end{array}$ & $\begin{array}{l}\text { - During the 52-week post implementation support period } \\
\text { - On-site support during the parallel run of the System } \\
\text { - Provide fixes for the Authority testing and acceptance } \\
\text { - Install the fixes on the production environment } \\
\text { - Problem identification and rectification support for defects in the components of the System }\end{array}$ \\
\hline
\end{tabular}


Appendix 8: Excerpt of The AOSS2 Database Design

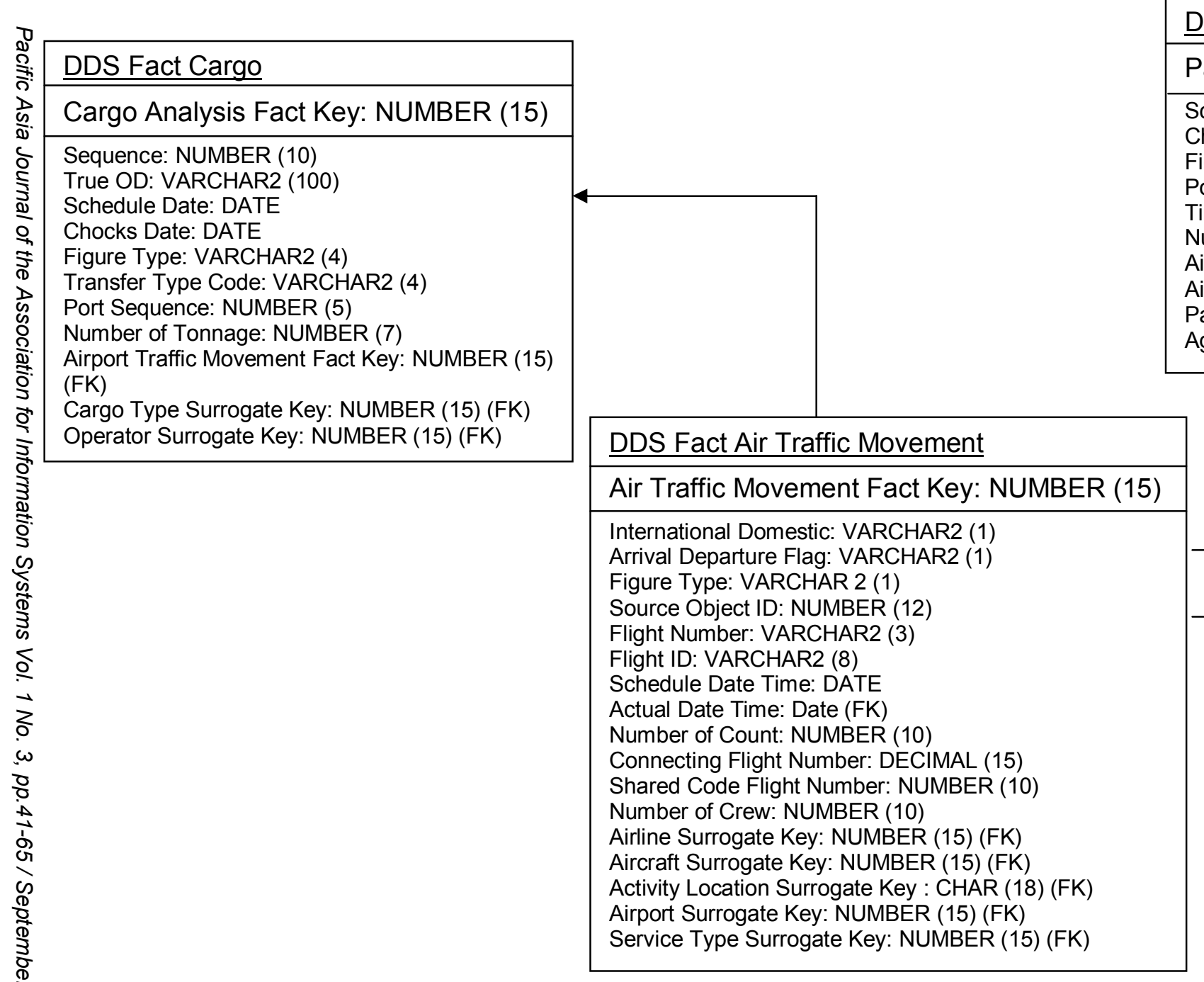

DDS Fact Passenger

Passenger Fact Key: NUMBER (15)

Schedule Date: DATE

Chocks Date: DATE

Figure Type: VARCHAR2 (1)

Port Sequence: NUMBER (5)

Time Value Date: DATE (FK)

Number of Passenger: NUMBER (10)

Air Traffic Movement Fact Key: NUMBER (15) (FK)

Airport Surrogate Key : NUMBER (15) (FK)

Passenger Type Surrogate Key; NUMBER (15) (FK)

Agent Surrogate Key: NUMBER (15) (FK)

\begin{tabular}{|l|}
\hline DDS Fact Intermodal Passenger \\
\hline Intermodal Passenger Fact Key: \\
NUMBER (15) \\
\hline Air Traffic Movement Fact Key: NUMBER (15) \\
(FK) \\
Number of Passenger: NUMBER (10) \\
Number of Baggage: NUMBER (10) \\
Schedule Date: DATE \\
OD Location: VARCHAR2 (20) \\
Figure Type: VARCHAR2 (1) \\
Time Value Date: DATE (FK) \\
Transportation Operator Surrogate Key: NUMBER \\
(15) (FK) \\
Nationality Surrogate Key: NUMBER (15) (FK) \\
Transportation Mode Surrogate Key: Number (15) \\
(FK)
\end{tabular}




\section{Appendix 9: Overview of Database Structure}

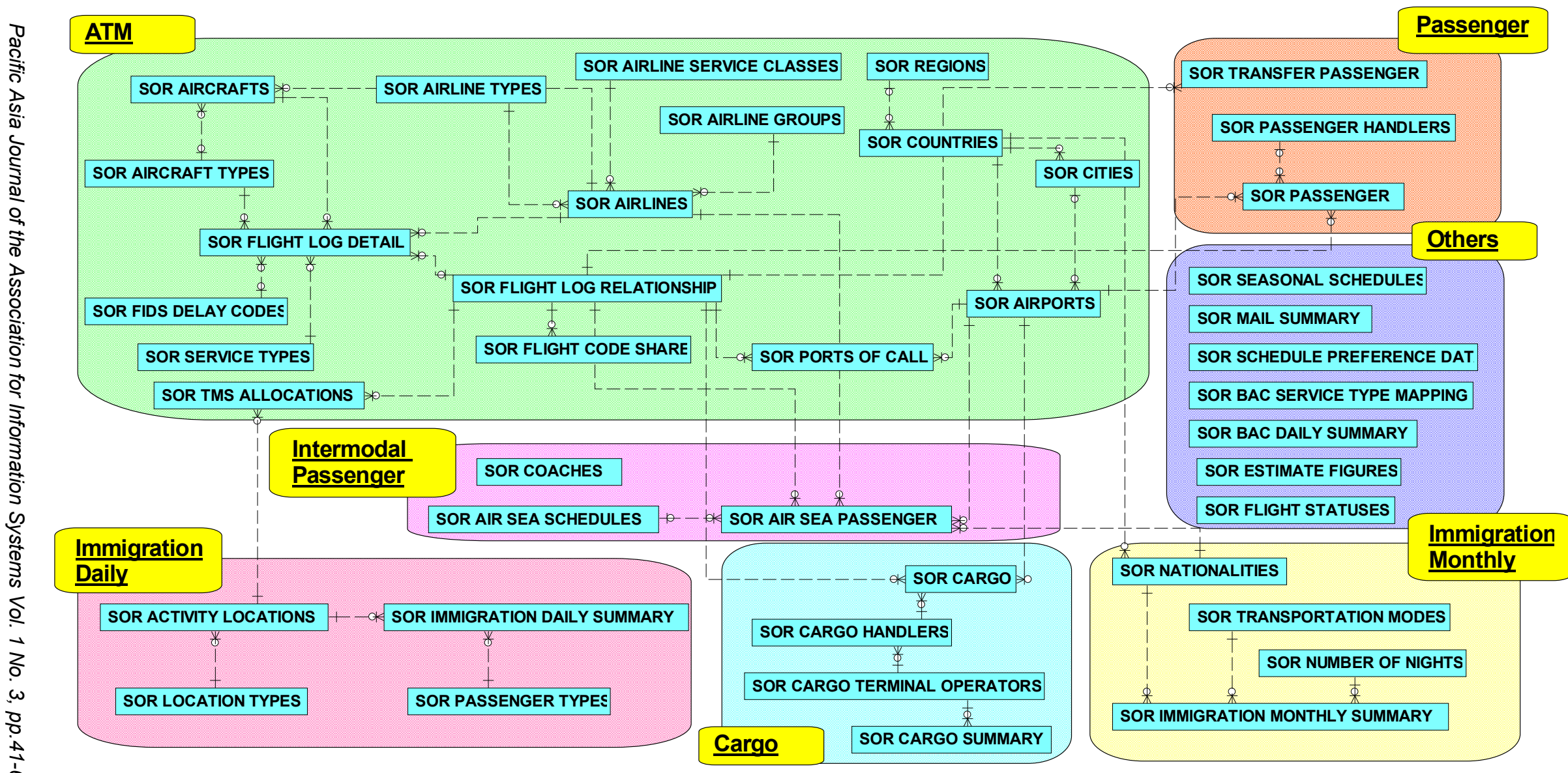




\section{Appendix 10: New System Function}

\section{Reporting and Analysis Capabilities}

BI System provides the below reporting capabilities:

- Ad-hoc Query Reporting

- On-Line Analytical Processing (OLAP) Analysis

- Executive Dashboards

- Static Reporting

\section{Ad-Hoc Query and OLAP Reporting}

Ad-Hoc Query functionality is provided by Cognos BI Query Studio, and OLAP tool, Analysis Studio.

The following are the functions of ad-hoc query and OLAP reporting:

- It allows end users to create, view and edit the previous OLAP \& Ad-hoc Query Reports.

- It provides slice \& dice, roll-up and drill down functionality through OLAP tool on predefined dimensions. It supports additional functionalities such as aggregation, sectioning, and filtering.

- It provides functionality to export the analysis results (In Reports) into Microsoft Excel or Adobe PDF format.

- It allows users to save pre-set report(s) into their personal folder for further modification on the report; given the user has the right to edit the original copy of the report.

- It supports drag-and-drop feature to swap from presenting data into tabular to graph, and vice versa.

\section{Query Studio}

BI provides an ad-hoc Query tool to support query data in Source of Records (SOR) of AOSS2 by end users.

\section{Analysis Studio}

Based on data available at Dimensional Data Storage (DDS) of AOSS2, analysis packages on the following areas have been built to fulfill analysis need.

1. Cargo

2. Air Traffic Movement (ATM)

3. Passenger

4. Combination of Cargo, Air Traffic Movement and Passenger

5. Skypier

6. Immigration (Daily and Monthly)

\section{DashBoard}

BI Dashboard provides an overview of key and summarized information with graphical interface for ease in illustration and comparison. The dashboard presentation provides customized information visualization specific to the airport's enterprise-wide business performance and process execution environment, with the provision of high level drill-down function based on defined dimensions.

The design and the underlying metadata layer defined for the BI Dashboard is flexible enough to cater future modifications provided that key performance indicators to be shown originate from data available in DDS. 


\section{Appendix 11: Illustration of the BI Dashboard}

\section{Daily Figures (04 April 2008)}

Passenger 101,271

MTD (yoy \%) $512,028(1.04 \%)$ Cargo (Tonnes) MTD (yoy \%)

\begin{tabular}{|c|c|c|c|c|c|}
\hline Statistic Types & Budget & Forecast & Estimate & Ext. Vs. Budget & Est.vs Prev. Year \\
\hline PASSENGER (‘000) & $3,900.011$ & $4,080.1$ & $4,090.24$ & $-4.7 \%$ & $4.2 \%$ \\
\hline CARGO ('000 Tonnes) & 339.32 & 311.81 & 316.21 & $7.3 \%$ & $0.0 \%$ \\
\hline ATM & 25,203 & 25,203 & 25,203 & $0.0 \%$ & $2.5 \%$ \\
\hline
\end{tabular}

\section{YTD Traffic Throughput (January 2008 - March 2008)}

\begin{tabular}{|l|l|l|l|}
\hline Statistic Types & Budget & Actual & Actual vs Budget \\
\hline PASSENGER ('000) & $11,656.17$ & $11,644.40$ & $-0.1 \%$ \\
\hline CARGO ('000 Tonnes) & 901.57 & 891.25 & $-1.2 \%$ \\
\hline ATM & $73,198.00$ & $73,208.00$ & $0.0 \%$ \\
\hline
\end{tabular}

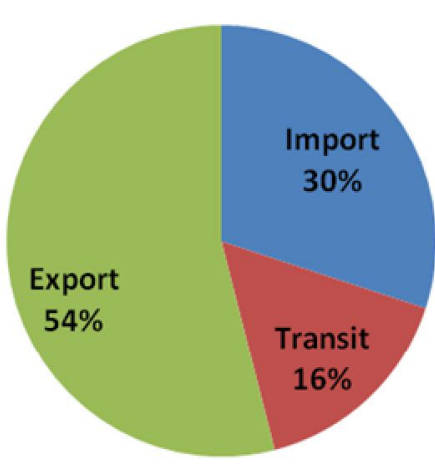

Cargo Actual Figure

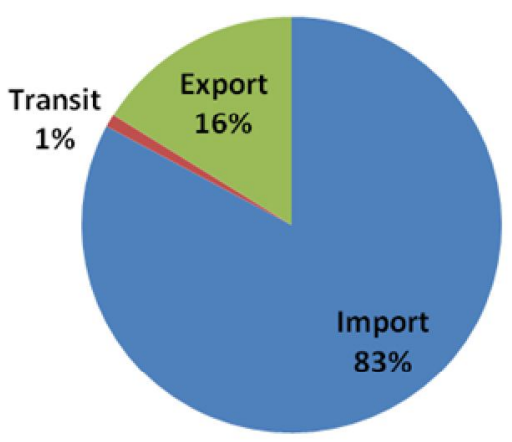

Air Traffic Movement Actual Figure

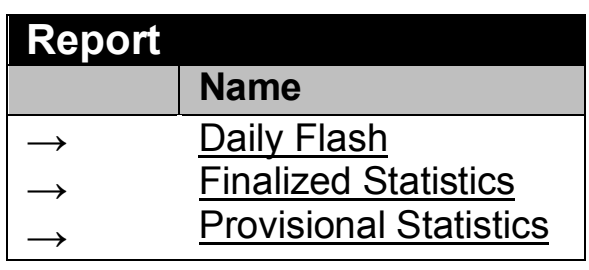

Passenger Actual Figure

Notes:

Source of Information

- Daily Passengers: Immigration Department \& AVSECO

- Daily Cargo Tonnages: Provisional figures from HACTL, AAT, FedEx and DHL, estimated tarmac cargo is included

- Daily Air Traffic Movements: AODB and BAC flights 


\section{Appendix 12: Comparison between Aoss and Aoss2}

\begin{tabular}{|l|l|l|}
\hline \multicolumn{2}{c|}{ AOSS } & \multicolumn{1}{c|}{ AOSS2 } \\
\hline Technology & Client based & Web based ride on EHF \\
\hline Login & Delegated AOSS Account & Single Sign On \\
\hline Deployment & Difficult & Simple \\
\hline Report Functions & Limited & Powerful \\
\hline Report Printing & Not Support WYSIWYG & Support WYSIWYG \\
\hline User Friendliness & Medium & Good \\
\hline On-line Data Analysis & Hard to implement & Easy to implement \\
\hline Ad-Hoc Query \& Search Functions & Nil & Yes \\
\hline Cross-divisional Reporting & Not Support & Support \\
\hline Exportability & Limited & HTML, PDF, Excel, CSV, XML \\
\hline
\end{tabular}




\section{About the Authors}

Andreas Schroeder, Ph.D., is a Lecturer for Information Systems at the Business School of the University of Buckingham, UK. After he received his Ph.D. in Information Systems from Victoria University of Wellington, New Zealand in 2008, he worked as a research fellow at the Centre for Applied Knowledge and Innovation Management, at the City University of Hong Kong, and at the Computing Department of the Open University, UK. He joined the University of Buckingham in 2010. His research focuses on the management of organizational knowledge and the use of social software, especially wiki technology.

Yulin Fang is an Assistant Professor in the Department of Information Systems, City University of Hong Kong. He earned his Ph.D. at Richard Ivey School of Business, University of Western Ontario, Canada. His current research is focused on knowledge management, virtual teams, and open source software projects. He has published papers in journals such as Strategic Management Journal, Journal of Management Information Systems, Journal of Management Studies, Journal of the American Society for Information Science and Technology, European Journal of Information Systems, Information \& Management, Communications of the AIS, among others.

Bryan Lee is a senior consultant in a global consulting firm, IBM Global Business Service. He earned his Master of Business Administration from City University of Hong Kong in 2008. He has been working in the IT industry for over ten years, mainly on the data warehouse and business intelligence areas. With extensive working experience in major corporations (e.g., UBS, HK Housing Authority, Airport Authority), he focuses on how to streamline project implementation efficiency by studying project knowledge management. 